Informatika i sistemy upravleniya. - 2016. - No. 4(50). - P. 3-10.

Gazizov T.T. (gtt@tspu.edu.ru)

Tomsk State Pedagogical University

\title{
EVOLUTIONARY MODELING OF THE TRANSMITTING ANTENNA COMMUNICATION SYSTEMS
}

New approach to the optimal communication systems design considered in this paper. The main characteristics of antennas, particularly to improve them by incorporating band-reject filters in their structure and optimization of genetic algorithms in the simulation stage. Results of the use of this approach in the form of a four-antenna synthesis with improved characteristics, obtained as a result of evolutionary modeling are shown. The comparison of simulation and experimental results submitted. Conclusions on the possibility of using the proposed approach for the different types of antenna transceiver improving communication systems are presented.

Keywords: evolutionary modeling, optimization, genetic algorithms, receiving transmitting antennas.

DOI: 10.22250/isu.2016.50.3-10

For citation:

Gazizov T.T. EVOLUTIONARY MODELING OF THE TRANSMITTING ANTENNA COMMUNICATION SYSTEMS // Informatika i sistemy upravleniya. - 2016. - No. 4(50). - P. 3-10. 